\title{
The Present as Past: Science Fiction and the Museum
}

MUSEUM

ENGAGEMENT AS

SPECULATIVE DESIGN

()

Open Library of Humanities

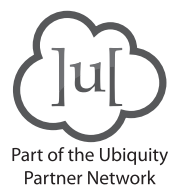

\section{ABSTRACT}

This article explores the role that science fiction (sf) texts might play in the museum, offering a perspective on acts of collection, curation, exhibition, and museum architecture, to ask what the museums of science fiction futures can offer those of us concerned with the role and responsibility of the museum in the present.

It draws together methods, content and reflections from a workshop held at the Horniman Museum with art and curation students from University of the Arts London in 2019, which explored the spaces and imaginaries of the museum. Over the course of this workshop, participants were asked to restage the museums described in three science fiction novels: H.G. Wells' The Time Machine (1895), Yevgeny Zamyatin's We (1924), and Sally Miller Gearhart's The Wanderground: Stories of the Hill Women (1979). By bringing the spaces of science fiction into the museum, these interventions reframed the terms of our engagement with museum objects and provided a site for broader reflection on the nature of museum design and practice.

This process of imaginative construction is extended into this paper, which crosses the fields of architectural design and theory, science fiction and utopian studies, and museum studies. It draws directly upon the interventions generated in the workshop, including photographs and descriptions which reflect on the critical potential present in multiple forms of knowing and the radical possibility inherent in collective acts of remaking. These fragments are used to direct research into museum practices, to situate these actions within wider theoretical contexts, and to explore the sciencefictional as a mode of thinking and making as well as a source text.

\section{CORRESPONDING AUTHOR:}

\section{Amy Butt}

University of Reading, GB

amyvictoriabutt@gmail.com

TO CITE THIS ARTICLE: Butt, A 2021 The Present as Past: Science Fiction and the Museum. Open Library of Humanities, 7(1): 9, pp. 1-18. DOI: https://doi.org/10.16995/ olh.634 
We follow the curator into the Horniman Museum object handing collection. Glass fronted cabinets line the walls, with curved tables and hanging displays that cry out to small hands and sticky fingers. Unlike the sedate spacing of the carefully labelled specimens in the Natural History collection, here the objects occupy the full depth of shelving. Stuffed birds peer over the top of seashells and the plastic pragmatism of an old mobile phone is lit by the reflected light of geode crystals.

We move through the room slowly, fighting the gleeful desire to squash our noses up against the glass, settling for whispering out marvels to anyone who happens to be standing near us (Figure 1). We are a small group of visitors: art and curation students from University of the Arts London (UAL), Dr Dan Byrne-Smith (Senior Lecturer in Fine Art Theory at Chelsea College of Arts and Art, Design and Natural History Fellow at the Horniman Museum), myself, and the curator who holds the keys to the worlds around us.

I shuffle my notes and step forward:

"Hi, my name is Amy (pronouns she/her). I wanted to start by thanking Dan for inviting me here, the Horniman staff for making this space available to us, and thank you all for coming along. Just to introduce myself, I am an architect and lecturer in architecture as well as being a passionate reader and advocate for the worlds of science fiction. So, over the course of this workshop we will be looking closely at the worlds contained in three science fiction novels: H.G. Wells' The Time Machine (1895), Yevgeny Zamyatin's We (1924), and Sally Miller Gearhart's The Wanderground (1979). These novels are all set in an imagined future and all contain descriptions of museums - spaces where our present is reframed as the historical past. In this workshop we will be restaging these described museums, to explore how bringing the spaces of science fiction into the museum might shift the terms of our engagement with the objects we encounter. In three groups we will select an object and then stage a re-enactment of the fictional museum as described in these short extracts using the materials in this room. What form this takes (an installation, a performance, a journey) and what aspects of the description it reflects is entirely up to you. Dan and I are both fascinated by the role that sf texts might play in the museums of our present, how they might provide us with the critical distance to consider how we think about museum spaces and the objects they contain, and what they might mean to us. We hope that today we can explore these questions together, through these acts of imaginative re-staging."
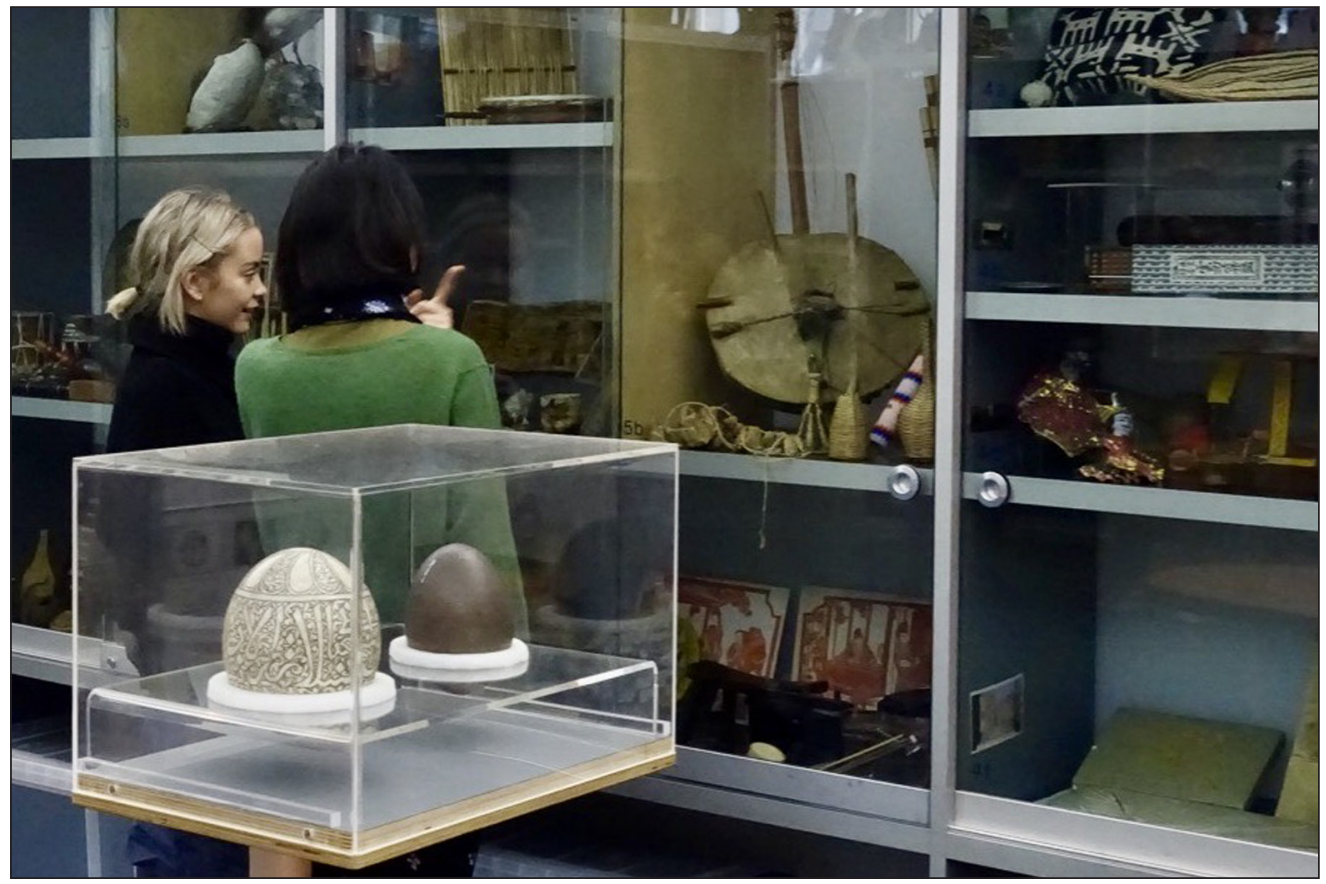

Science fiction ( $\mathrm{s}$ ) allows us to inhabit imagined worlds, providing us with memories of lives as-yet unlived which we carry with us alongside the memories of our own lived past. In Archaeologies of The Future, Frederic Jameson discusses the science fictional in utopian texts pen Library of

Humanities

DOI: $10.16995 /$ olh. 634

Figure 1 The object handling collection. Two people stand in front of a wall of glass cases containing a variety of museum objects. In the foreground, there is a glass case containing two ornately patterned eggs. The way the eggs are arranged in the case is similar to the way the two people are standing together. One of the people is smiling while pointing towards a musical instrument within a case along the wall.

Reproduced by permission of Dan Byrne-Smith. 
in terms of its ability to function as a memory trace, an ability to communicate "messages of otherness but transmitted in the past" (Jameson, 2005: 99). In these fictions the materials and moments of the present are reframed as memories, a small part of the improbable history of imagined futures. To move through the museums described in sf novels is a temporally estranging experience.

In their work on speculative design, Dunne and Raby (2013) talk about the speculative in terms of a set of events which might lead us from here to there. But, perhaps more importantly, they call for the speculative to perform a critical function, and it is on those terms that this workshop and article considers sf: as a critical design tool which allows us to reflect on the world we inhabit. It draws on Darko Suvin's description of sf as a genre of cognitive estrangement to examine fictions that provide "not factual imitations of a better world, but illuminations of the way we imagine this one” (Williams, 2014: 627; discussing Suvin, 1979).

Just as this workshop uses the worlds of sf to create a critical distance from lived reality, so this article has drawn upon the experiences and interventions generated in the workshop to direct research and prompt reflection into museum practices. Between the descriptions of the workshop (printed in this essay in italics, accompanied by hasty photographs taken on phone cameras), it draws on architectural theory, science fiction and utopian studies as well as museum studies to understand and situate these actions within wider theoretical and practice contexts. In both the workshops and this article, the science-fictional is a mode of thinking as well as a source text.

We divide ourselves into three groups. Each group picks up a note card onto which is printed a small extract from a novel. Our eyes continually dart up to the eclectic exuberance which surrounds us, a weight of stories which presses in on us. The descriptions of fictional museums are echoed in the display cases, these preserved fragments of our material present. Several people from each group read the extract aloud so no one voice holds ownership over its contents. As the curator opens the cases each group steps forward to select an object, holding it between them to consider how it might be understood within the strange new world they will be making.

\section{THE TIME MACHINE}

I found the Palace of Green Porcelain, when we approached it about noon, deserted and falling into ruin. Only ragged vestiges of glass remained in its windows, and great sheets of the green facing had fallen away from the corroded metallic framework... Going towards the side I found what appeared to be sloping shelves, and clearing away the thick dust, I found the old familiar glass cases of our own time. (Wells, 2016: 61)

For the time traveller in H.G. Wells' The Time Machine, written in 1895, the Palace of Green Porcelain is an image of a future which resonates with the values of progress he carries with him. It is a direct descendant of the museums of South Kensington which Wells was intimately familiar with as a student at the Normal School of Science, and a reference to the Crystal Palace which opened in 1851: Victorian industrialization and imperialism inscribed in the architectural languages of iron and glass and delicate porcelain. As described by Katie Stone, the traveller aligns himself with the "imperialist strand of evolutionary thought" (Stone, 2020: 50), made manifest in the linear temporality of the museum exhibitions where the atrocities of imperial colonisation are overwritten by the narrative of progress which situates the heart of the Empire as the pinnacle of civilization. ${ }^{1}$ This seizure of the bodies and works of colonised peoples is accompanied by their positioning within imperialist narratives of development as the spectacle of a still-present past. In the Palace of Green Porcelain, as in the museums it echoes, colonialism has made space into time (Rieder, 2012; cited in Stone, 2020).

We gradually become unaware of one another within the object-handling collection, each group focused on the extract and object they have chosen. Small circles of close observation are created, closed off from one another by the intensity of our gaze inwards. Reluctantly we are pulled together as the first group reads their short extract from 'The Time Machine' aloud. As quiet

1 While the complex relationship between the nineteenth century museum and imperial colonialism is beyond the scope of this article, this reading was based upon the work of Barringer and Flynn (2012), and Bennett (2013).
Open Library of

Humanities

DOI: $10.16995 /$ olh. 634 
falls again, we stand awkwardly in the centre of the room, waiting for them to share an object, to open a discussion, to take some action to spin us into purpose. But the group responding to this extract stalls our pre-emptory movement as they quietly explain that both object and response are already in place. The process of selection and curation has taken place without us.

In The Time Machine the Palace of Green Porcelain stands in ruins. Inside, the ranked cases which speak to the time traveller with such reassuring certainty have been remarkably preserved, but they are no longer of interest to the peaceful Eloi people who have seemingly evolved beyond the need to strive or want. Instead, its sloping floors spatialize another form of progress as they lead down to the darkened subterranean city of the Morlocks, their existence below the world of the Eloi a manifestation of the exploitation and violence which both underpins and undermines the veneer of civilization. ${ }^{2}$ The linear narrative of scientific advancement contained within the cases is disconnected from the present of the ruin, that measure of progress having peaked and plateaued and been rendered no longer relevant.

We try to refocus our attention, to identify what has changed, seeking out some trace of the change which has been made while our focus was directed elsewhere. But in this room lined with a wild exuberance of museum objects it is hard to discern something out of place. Whatever act of relocation the group has performed in selecting an object and constructing a response, it is camouflaged by the chaotic decontextualization of the other museum objects which surrounds it, objects which are already out of time and out of place.

In this state of partial ruin, the Palace of Green Porcelain confronts us with impermanence and temporal distance on two scales; while the presence of the museum and its exhibits suggests that the dust has only just settled on a future that is not too distant from our present, the loss of recognisable humanity to new evolutionary development sets it at a distance measured in epochs (Parrinder, 1995). It is a monument to the inevitability of change and decay, which acts on both the human body and cultural constructs of knowledge. While the Eloi may be able to run their hands along the smooth surfaces of the glass cases and observe the objects which have been perfectly preserved, they have no desire to traverse the conceptual distance which separates them from the objects within.

The group who have staged this response share glances with one another. Eventually someone nods towards to a cloth in one corner of the room. One person steps forward to grasp its edges and, aware of our focused attention, they remove it with a flourish (Figure 2). The role of the cloth is revealed at the same moment as being swept away, an echo of dust sheets placed over soft furnishings as shroud and shelter. The dramatic nature of the gesture grants this overlooked corner narrative presence in the same way that a theatre curtain drawn back and the anticipation of staging speaks of a story to be told.

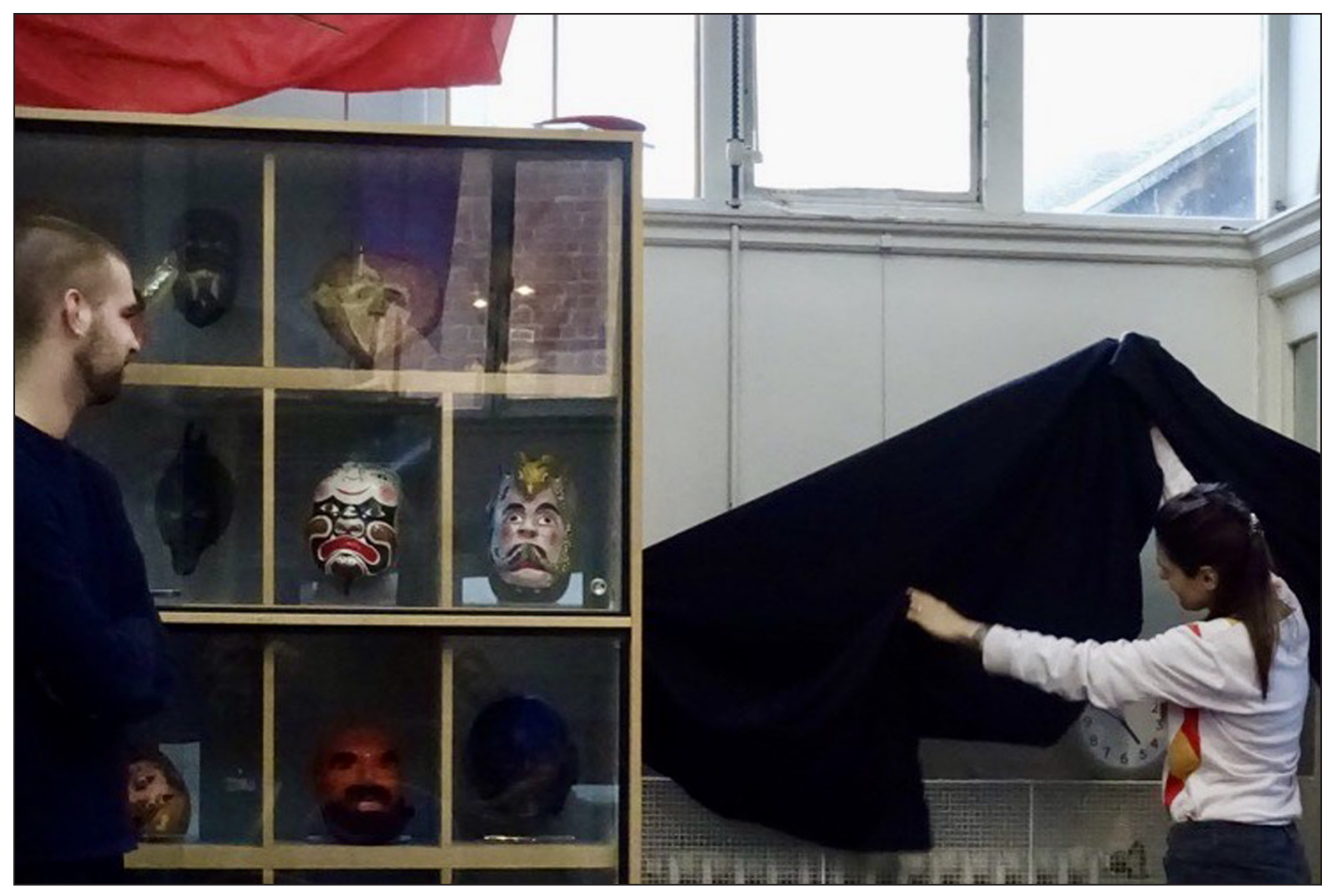

2 The symbolic significance of the spatial relations between the Eloi and Morlocks is further explored by Beaumont (2012) and Ketterer (1998).
Open Library of

Humanities

DOI: $10.16995 /$ olh.634

Figure 2 The moment of revelation. A person is in the process of lifting up a black piece of fabric to reveal the corner of the room which was hidden behind it. Another person stands at a distance and looks on, and their gaze is echoed in a glass case filled with masks which line the wall and look out at the camera.

Reproduced by permission of Dan Byrne-Smith. 
Within the narratives of sf, Susan Sontag (1964) delineates the recurrent appeal of an aesthetic of destruction, the allure of imagined futures which decimate the built present, leaving only a ruin, the catastrophic failure to maintain our contemporary moment. But for Vivian Sobchack (1988) the wonder within these ruined futures comes not from the act of destruction but from the subversion of the familiar. For Sobchack, part of the appeal lies in the estranging presence of the familiar within the landscape of a far future, or in the object whose narrative connection to our present is maintained despite the destruction which surrounds it.

We talk about what it means to reveal something, to be provoked into the shocked recognition of the familiar, to sweep away the layers of dust, time or unseeing which have hidden some part of the world from us. Someone draws a distinction between that which is overlooked and that which is concealed, and the blurred edges where the insidious subtleties of privilege and power constrain access to knowledge. We talk about the nature of agency, and the difference between not knowing and being invited to discover.

In the ruins of these imagined futures the objects which are imagined to survive us are chosen, in part, for the role they take on within the narrative. But while the cases of the Palace of Green Porcelain contain a pack of sulphur matches which go on to serve as a utilitarian narrative device, the matches also retain their symbolic weight as testament to scientific knowledge systems which are deemed to have been lost. As described by Robert Crossley in relation to the museum in sf, "the spectacle of an observer examining an artefact and using it as a window onto nature, culture and history permits the convergence of anthropological, prophetic and elegiac tonalities" (Crossley, 1991: 206). The impossibility of fully describing the entirety of an imagined world within any single sf text means that the objects, artefacts and spaces they contain cannot afford to be inconsequential (Jones, 1999), and as such they invite close and critical examination as windows into a world.

Beneath the cloth sits a stuffed bird. The vitality in the lustrous texture of its wings is belied by its flat black eyes, fixed in this singular moment. It is balanced on a projecting skirting board, propped between the door frame and a radiator (Figure 3). Both radiator and bird were concealed by the cloth and both are rendered remarkable when revealed, the visibility with held by the cloth snapping back into place to create a heightened attentiveness. The performance of concealment and the forced focus it creates grants significance to these objects, it implies that they will withstand and warrant the pressure of our scrutiny. We are impelled to create the reasons for their preservation.

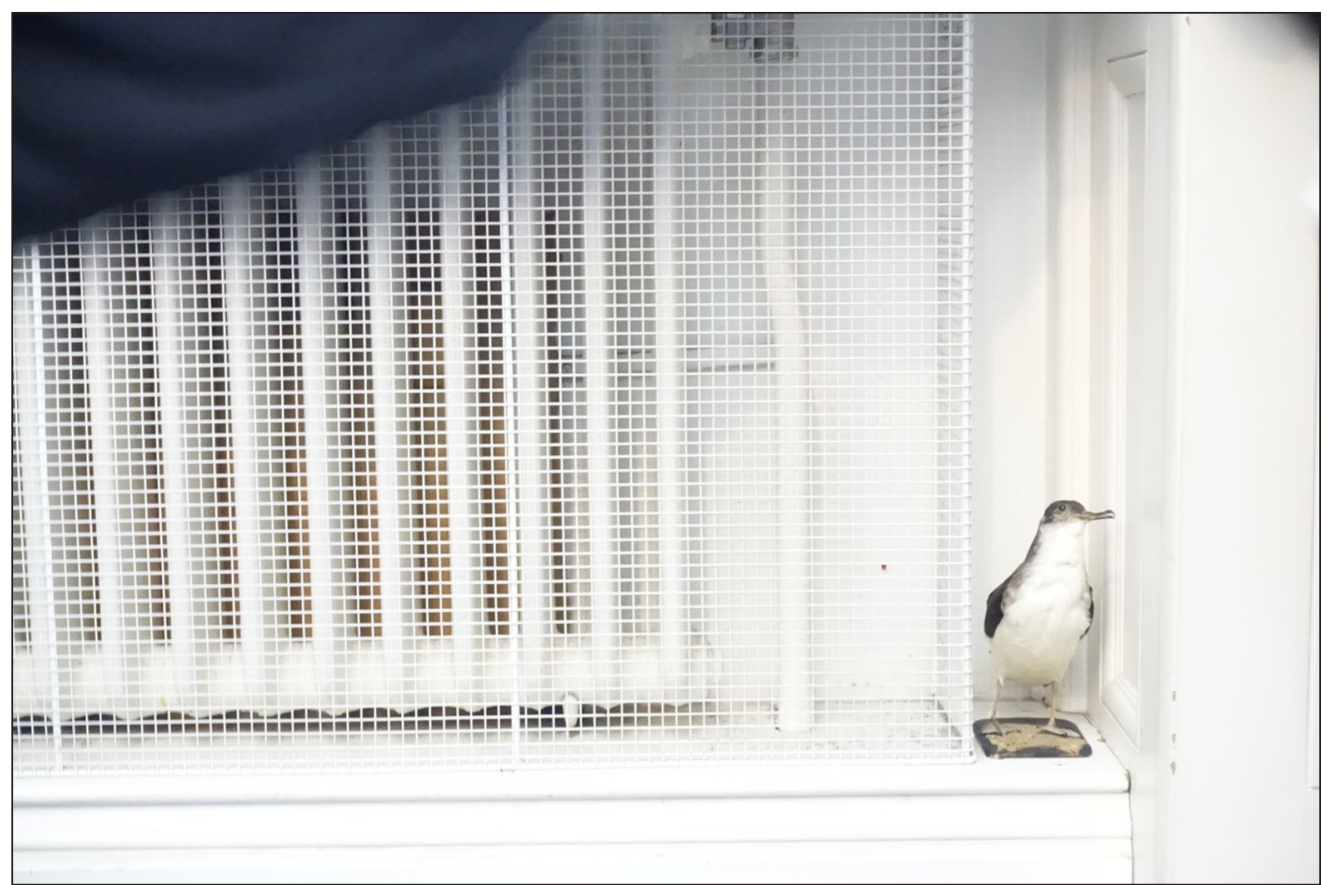

pen Library of

Humanities

DOI: $10.16995 /$ olh.634
Figure 3 The concealed object. An industrial radiator is enclosed in a protective wire cage, with a small gap between the radiator and $a$ door frame. A small stuffed bird has been placed in this gap, balanced on the top of a projecting skirting board. A small amount of black fabric is visible draped over the top of the radiator. Reproduced by permission of Dan ByrneSmith.

3 This follows Barthes' observation that objects are never without meaning in a narrative sequence, as "everything, in one way or another, is significant" (Barthes and Duisit, 1975: 245). The object within sf is an intensified instance of this, carrying the weight of communicating a story-world which cannot be presumed into existence. 
These objects out of time, imaginatively displaced into the future, act as a material record of our present. They stand as a proxy for our contemporary selves or a conductor of personal or cultural memory within the imagined future. But they are also wrapped in the interpretive understandings of their estranged temporal context, as in novels like Ray Bradbury's Fahrenheit 451 (1953) or Walter M. Miller Jr.'s A Canticle for Leibowitz (1959) where the books which survive the flames are imbued with new meaning as a source of revolutionary hope or a record of apocalyptic hubris. This constantly shifting meaning is explored by Susan Crane (2006) in relation to museum objects, who posits that the purpose of the ruin or relic is not fixed but is multiply constrained and reformed by historical context.

Someone asks whether the same act would affect other objects, so we rummage in pockets and bags for the detritus of the everyday. Hidden within our palms so as not to spoil the surprise, we place these objects beneath the same cloth and step forward to perform the same flourish of revelation. The objects we put forward are violently stripped of context before being placed under collective consideration. They are bestowed with value and heavy with meaning.

As the relics and ruins within the imagined futures of sf compel close examination, they provide vital ground to confront the material conditions of the present. The temporal distance of imagined futures bestows these objects with new significance through which their social, cultural and ecological implications can be revealed. As noted by Richard Crownshaw (2017), this makes sf a genre uniquely situated to grapple with the Anthropocene. It is able to engage with scales of space and time not available to other forms of fiction while still establishing empathetic connection to individuals as they confront vast systemic issues, such as climate crisis. ${ }^{4}$ In these fictions the repercussions of our actions in the present can be explored, and the tangible presence of objects provides the evidence against which we are held accountable. For the reader, the experience of speculation provoked by these objects is deliberately multiple in order to elicit such critical reflection, and as Lizzie Muller suggests, "in the interplay of their impossibility, obsolescence and liminality with their tangible existence, these objects act not only as mirrors of our own reality, but also as portals that allow us, if only fleetingly, to move beyond it" (Muller, 2013: 5).

We question a camera lens cover for the longest time. Its use is not immediately apparent until it is picked up and held. Someone talks about its specificity: the reliance on its partner object to grant utility, devoid of function in and of itself. Someone else refers to its manufacture, the knowledge of petrochemistry present in plastic, and the machine and human labour implied by its fine precision. We are confronted with the contradictions of centuries of scientific progress manifest through technical complexity and its planned obsolescence. It contains and expresses multiple scales and notions of time; the constructed human histories of industrialisation set against the geological time held within the oil of its plastic and the future ages of its gradual decay.

Through this re-enactment of the science fictional museum space, the materials of the collection and the mundane contents of our bags and pockets are recontextualised as relics in an imagined future. As such, they invite the complex processes of interpretation which such fictions would inspire, where dialectical objects out of time provide a complex commentary on the value systems which governed their production. This process offers a radical disruption to the temporal context of a museum object from the curated past into an imagined future. It is a reframing which allows collection objects to be situated within the broader context of urgent global challenges, and as such, it is a process which might support wider efforts to engage museum visitors in critical reflections on climate catastrophe, and the vital work being done to instigate cultural and legislative change through public pressure.

\section{WE}

Then a slight, involuntary sinking of the heart - down, down, down, like descending a steep hill - and we were at the Ancient House. The whole, strange, fragile, blind structure is wrapped in a glass shell: otherwise, of course, it would have collapsed
Open Library of

Humanities

DOI: $10.16995 /$ olh. 634 
long ago. I opened the heavy, creaky, opaque door and we were in a dark disorderly space. All the lines created by the furniture all mangled by that epilepsy, not adhering to any sort of equation. I bore this chaos with great strain. (Zamyatin, 2007: 24)
Open Library of

Humanities

DOI: $10.16995 /$ olh.634

Yevgeny Zamyatin's novel We, written in 1920 and first published in English in 1924, presents a dystopian future of totalitarian control, where the cold logic of mathematics permeates a society operating in calculated accordance with strictly delineated systems of time and collective purpose (Parrinder, 1973), suppressing or forcibly excising the individual swell of emotional or fantastical longings. Each citizen lives and works within glass structures, a crystalline city as unyielding and unforgiving as the One State which it materialises, which imposes a panopticon of ubiquitous visibility. ${ }^{5}$ In the architecture of We there are no window cleaners and no rain-stained patches which would impede the ability to observe and be observed. The flawless perfection of the glass refutes failure or frailty, and implicitly dismisses any need for care.

The extract from 'We' is read aloud and the group step forward holding a bird's nest. It sits on a bed of tissue paper, loosely held within a white cardboard box. The lid which covers the box is clear plastic, with ripples of opalescent white at the corners where the stress of the bend has pushed past the limits of transparency. We gather around to peer in through the lid.

Within this strictly bounded, systematic and homogenous world, the Ancient House stands as an aberration of dark corners and twisted stairwells. It has been selected to be preserved by the One State as monument to its own empirical superiority, a physical fragment of an obliterated past maintained in order to further sustain the systems of power and control that claim to have superseded it. This is reflected in the architecture of the glass dome which surrounds it, acting as a museum display case scaled up to contain a singular exhibit and sealed against the ravages of heat, moisture, or dust: a perfected enclosure which denies the possibility of time and change.

As we peer into the box, someone speaks about the complexity of the nest within, the apparently chaotic gathering of twigs which resist precise and repetitive patterns but still manage to cohere into a composite whole. Someone refers to the nest sitting within its box as barely contained complexity. At a careless glance it is easily dismissed, so familiar it can be mistaken as simple, but by following the careful bend and weave your eye falls into the small dark spaces caught tight between the twigs. It is a vertiginous composition.

In this short extract the protagonist D-503 visits the Ancient House for the first time, a journey which James McClintock (1977) likens to a descent into a netherworld, traversing the boundaries of life and death, rationality and irrationality. Once inside, D-503 is overwhelmed to the point of emotional crisis and physical collapse by the dark disorder of the Ancient House; its very existence is a refutation of the logic which has governed his life thus far. In this museum there is no attempt to assist the visitor with the softening comfort of the explanatory notice; on the contrary, it is a deliberately jarring experience designed to present the past as incomprehensible and inspire feelings of revulsion and dismay. But this existential disorientation also forces a process of critical interpretation, and in doing so, provides a point of connection to the past through the ideas of individual choice and subjective understanding which are denied by the One State (Gheran, 2014). The very absence of applied layers of meaning forces the visitor to confront the stark alterity of the Ancient House, and demands a reciprocal reassessment of the present.

The person carrying the box holds it with both hands and carefully keeps it level. As they move with caution, we become aware of the disjunction between our responses to this object and the desires that drove its creation. To the bird it was a protective enclosure, constructed with great care to shelter and hold fragile eggs whose shells, in turn, enfold a future. It is now encased in layers of protection in an attempt to create stasis: the tissue paper; the box; our careful hands.

Hannah Arendt argues that one of the ways in which totalitarian regimes ensure the continued domination of their subjects is by the manipulation of their relation to time itself, through the denial and destruction of the materials and moments which served as evidence of a time

5 The symbolic, social and cultural implications of the architecture of We has been subject to critical attention. In particular, its relation to contemporaneous Soviet architecture has been examined by Hutchings (1981), while Gomel and Weninger (2004) consider it in terms of the wider symbolism of crystal and glass in utopian literature. It is an architecture which speaks of dualistic oppositions, but also serves to critique such modes of thinking. As Luke Jones (2018: 7) notes, the Green Wall that surrounds the One State is a structure which "simultaneously encloses and absolutises the Utopian order, but at the same time dramatises, and undermines, this very act of boundary-setting." 
outside of that system (Arendt, 1973). The Ancient House is intended to form part of a denial of time outside of the One State through the controlled containment of the past. It establishes a strict delineation of insurmountable difference between the fixed points of then and now, as a demonstration of the ideological superiority of the unchanging present.

But, while it is hermetically sealed and controlled by the One State, the Ancient House persists as a fragment of history which maintains the possibility of difference. Here the physical and temporal edges of the One State are made visible, both in the boundary which spatially encloses the house and implies that this condition is not present everywhere, and in its temporal enclosure of the remnants of a past which suggests a beginning and creates the hope for an end. As Phillip Wegner (1993) notes, the Ancient House becomes a site of radical potential within the novel, a site for illicit and unexpected acts of humanity. It is a passage into other worlds and a utopian enclave. ${ }^{6}$

As we discuss the nest and examine its fragility, we describe our growing need to see it protected, coupled with a more poetic desire to express and experience the intricacy within the nest that the box has muted and held distant. We stand up and begin to reposition our folding chairs: objects which were designed to support human bodies now repurposed in defence of the nest. Both chair and nest as sites of rest have become unsettled. Turned on their sides, the seats cradle the nest in the crook of the bend, while the legs project outwards. As more chairs are stacked in a circle it becomes more precarious, a mutually constructed act of balance (Figure 4).

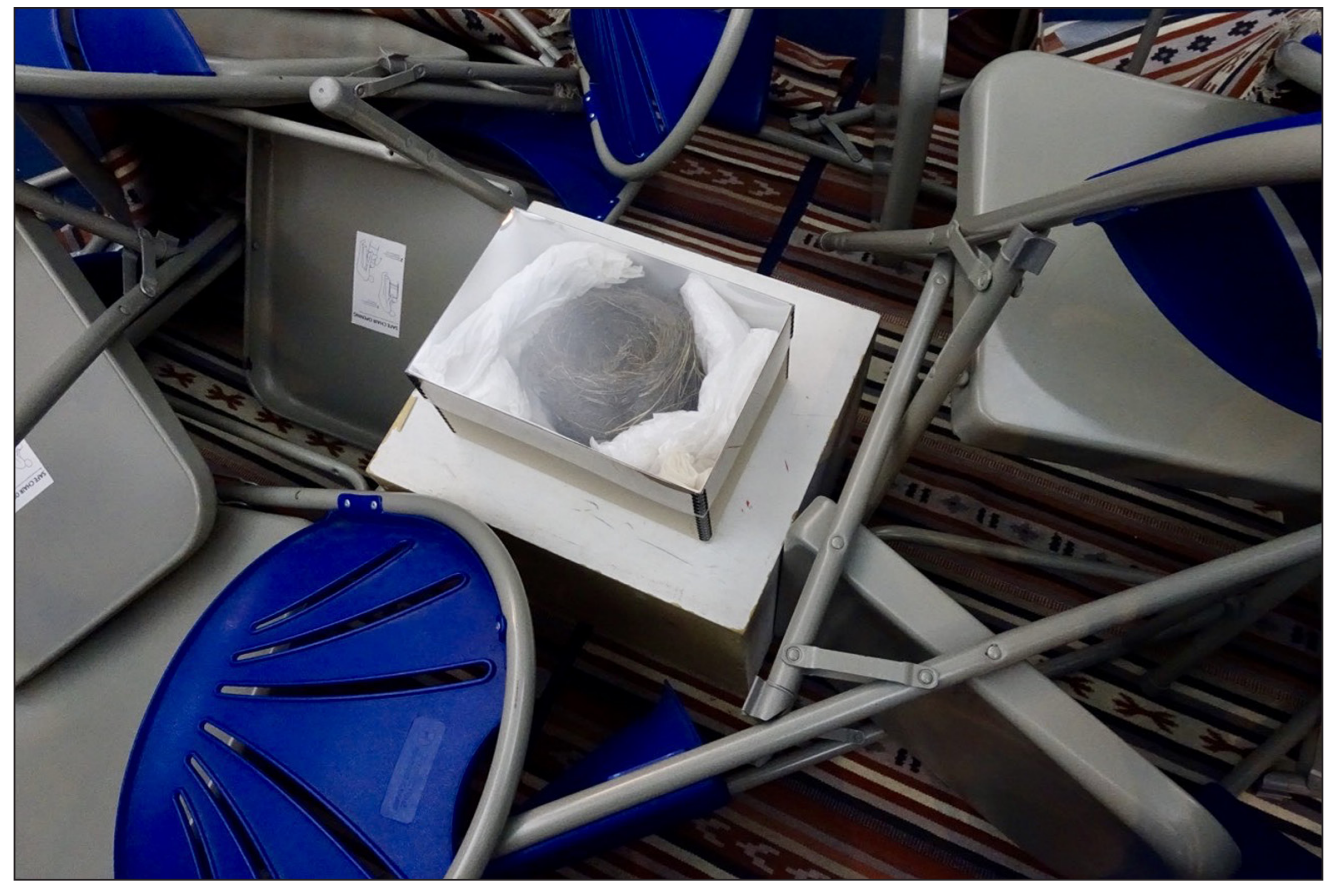

As opposed to the fictional futures of the ruin where the focus is on objects that are imagined to have survived despite their circumstances, in We the historical object has been selected and subject to sustained acts of conservation. The selection of the Ancient House is an act of collection, described by Rebecca Leach as a process by which "ordinary things are made extraordinary" (Leach, 2002: 153; cited in Fyfe, 2006). While collections range from the personal to the institutional, they share the intention to protect that which has been selected.

Our nest of chairs is a violent structure. Its form implies a threat and conjures an imagined world of hazards which lurk beyond the circle, validating a fear of the unknown by existing as a defence against it. But while the projecting legs spike outwards with an unforeseen ferocity the precarity of the structure undermines its security; it is as likely to cause harm as to prevent it.

A collection is not only a material archive of preserved pasts but, as noted by Patricia Davison (2005), it is also a record of the concerns which governed its own creation, as is present in the One State's desire to contain alterity. In the act of selecting objects for conservation they are
Open Library of

Humanities

DOI: $10.16995 /$ olh.634

Figure 4 The protected object. A bird's nest encased in a plastic box sits on top of a small white plinth at the centre of the image. Folding chairs surround the plinth, balanced on top of one another in a way which makes it difficult to discern any individual chair. The interlocking grey metal legs of the folding chairs echo the woven twigs of the bird's nest. Reproduced by permission of Dan Byrne-Smith. 
identified as being both at risk and worth the work of preserving. They are decontextualized and imbued with new meaning and value. For the objects housed within a museum or archive, the institutional weight applied to this act establishes the collection as an anchor of authorised memory, a discursive site for the production of reality (Crane, 2000). Through the accumulation of material culture and the control of historical narratives, power is legitimised and entrenched (Macdonald, 2006). A such, it is here that knowledge and experience are designated as marginal, subject to appropriation and patterns of unseeing which passively dismiss or actively censor, and are intentionally suppressed or violently overwritten.

The growing stack of chairs becomes an argument for itself. Each seat that we move into place becomes an act of protection that makes the object contained seem more vulnerable and more precious. As we build, we reflect on the nature of fragility, how our actions re-inscribe this object's importance and reiterate its value. Like the plinth beneath the nest, our performance of concern elevates this object, encircling it with our time and labour, while making it all the more difficult to reach.

This act of care resonates with the desire identified by Susan Crane to "preserve, protect, and defend the objects we choose to represent our pasts and our cultures because that choice, that representation, is itself valuable to us" (Crane, 2006: 108). As such the work of maintaining existing collections is a fundamentally conservative act, allowing both the object and conceptual frameworks which are manifest in the privilege of making such a choice to perpetuate, by sustaining them against decay and preserving them from failure. However, this maintenance work also serves to resist narratives of linear progress, existing in what Lisa Baraitser (2017) calls stuck or enduring time which creates moments of impasse. These are places where the labour of care which underpins maintenance work can be witnessed and valued. While individual objects appear to be frozen in stuck time as active selection intervenes in passive eternity (Crane, 2006), it is an illusion of continuity made possible because of the unremitting labour of curatorial and custodial staff.

The stack shifts suddenly and one person steps forward to hold their arms over the nest within (Figure 5). It is an instinctive action, limbs continuing a movement which starts with an abrupt twitch of concern. They form a shelter with their body against the risk we have created, creating a barrier with their skin and bone. It is an act borne of a rapid valuation which places this object, experienced and known only for an hour, and the collective guilt of its loss, over personal physical pain.

They remain there until we have cleared the chairs away.

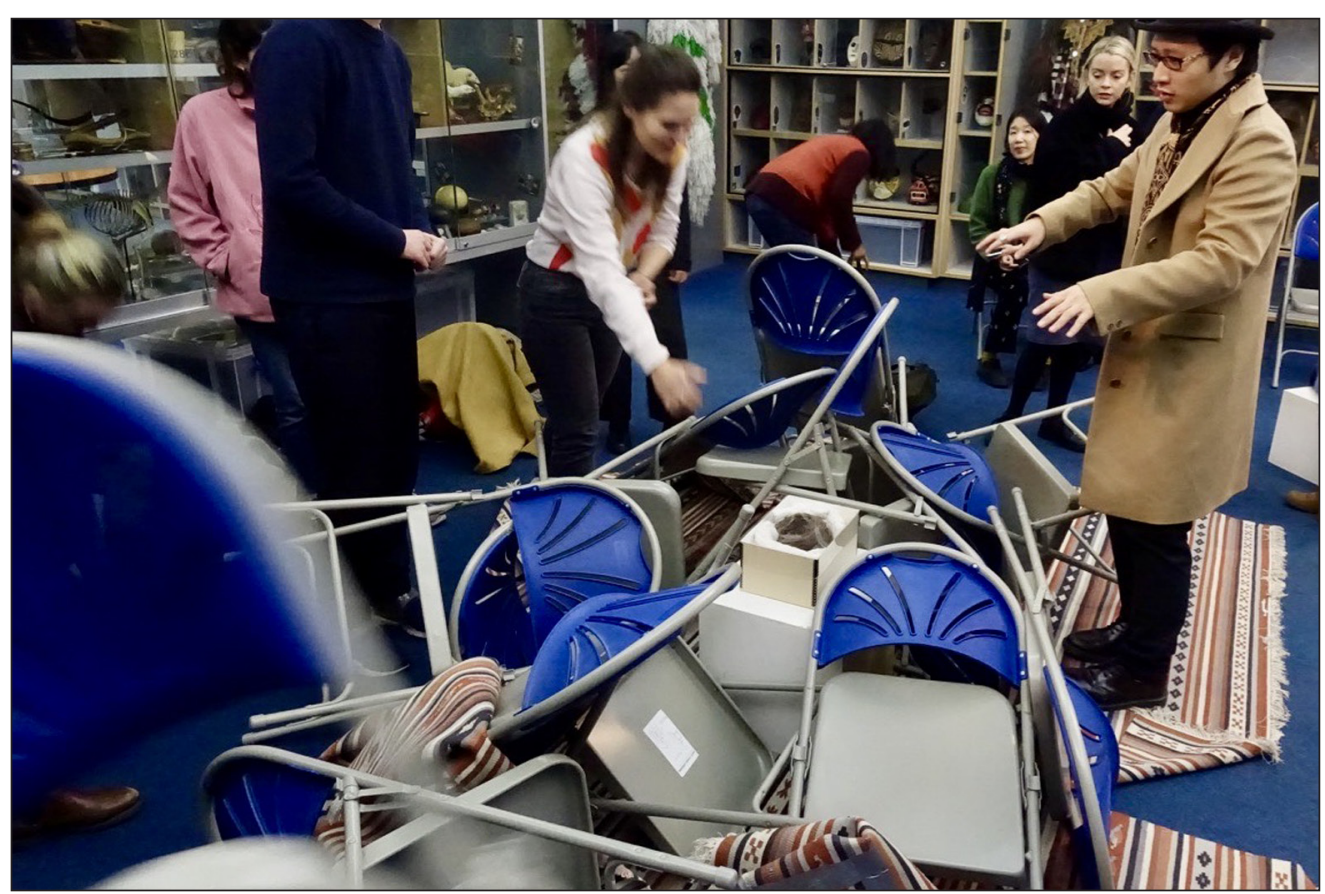

$7 \quad$ The complexity of reconstituting histories which have been suppressed, dismissed, trivialised, appropriated or overwritten, while also resisting their being subsumed within the ideological dominance of prevalent or powerful narratives, has particular resonances with the work of Afrofuturism (Bould, 2019; Yaszek, 2006). As detailed by Kodwo Eshun (2003) Afrofuturist fictions utilise intentional and necessary dislocations of time to create and reinstate both counter-memories and counter-futures.
Open Library of

Humanities

DOI: $10.16995 /$ olh. 634

Figure 5 The protective structure. A bird's nest encased in a plastic box sits on top of a small white plinth. Folding chairs have been haphazardly stacked around the plinth, including a chair which partially obscures the image. Several figures look on while two people gesture towards the stack of chairs, one of whom is in the process of reaching out to hold a chair steady. Reproduced by permission of Dan Byrnesmith. 
The objects contained within the museum have been carefully selected, continuously maintained, and conscientiously conserved. While our re-enactment of The Palace of Green Porcelain allowed us to consider the temporal estrangement of the object and prompted reflection on the value systems which underpinned its manufacture, our re-enactment of the Ancient House provided a critical distance to consider how acts of collection and protection imbue their chosen objects with value and act as a record of the concerns which governed their preservation, which are enmeshed in considerations of power and cultural dominance.

Through our performance of preservation inspired by the Ancient House, we enacted an understanding of the collection as a social product, reliant on continual acts of maintenance to sustain each individual object. This reframing provides a space to consider how decisions about collection and curation are remade in each moment, and by extension, how the systems of knowledge that these collections validate are being continually reproduced. By situating these objects within museums of an imagined future, the responsibility for their presence is understood as something which must be addressed in the present, rather than being an inherited product of a distant past. It is a perspective which might support the vital work being done to critically re-examine collection practices. If we can understand museum collections as being continually sustained and remade, our present moment is complicit where these curatorial systems reinforce or perpetuate practices of oppression.

\section{THE WANDERGROUND}

She scrunched into the niche she had built for herself: a large heap of small pebbles which made a backrest and a mound of pebbles and coarse sand that curved around to rest each of her arms... Around her in the windowless chamber were nearly a dozen other girl-children who were digging out and settling into their places amid giggles and chattering.... "Once upon a time..." It was Alaka's rememberings today which drew Clana and her sisters into the past... "Once upon a time..." Clana whispered with all the others. (Gearhart, 1979: 138)

This scene, of girl children huddled to hear stories of the past, is one of several distinct glimpses into the world of the Hill Women which are collected in The Wanderground. The novel portrays a gender essentialist and separatist feminist future where groups of women have fled the cities of men to establish communities in the hills. ${ }^{8}$ While the technology in the cities is comparable to that of the time of writing, the communities of women have developed new abilities and ways of living (Khanna, 1984). As such, it presents a coexistence of future and present, as a society which, according to its own telling, has moved beyond the violence of the cities alongside those still mired within contemporary patterns of exploitation.

An object is wrapped in tinfoil. The scrunched texture disguises its appearance and shape, creating a new form which wraps around the object within. It is held by a group who sit in a circle on the floor. After reading the short extract from 'The Wanderground' they ask us to surround them with chairs and to drape a rug over the top, to hide and enfold them as tightly as the object.

Within the communities of the hill women, the 'remember rooms' serve as a site for collective memory. There are racks of objects, both found and sought out, which serve as prompts to educate the community's children about life in the cities. In contrast to the world they occupy, the cities are presented as grotesque spaces where commodity or fetish value supersedes human rights and agency. In the remember rooms the objects speak directly to the visitor, with labels that audibly narrate the individual experiences of the many members of the community who have interacted with them. They establish an interrelationship between personal experience and object, making manifest the complexity of interpretation and exposing memories of oppression and exploitation. For Angelika Bammer, "Gearheart collapses the distinction between history and story by suggesting that they are made of the same material" (Bammer, 2004: 81). en Library of

Humanities

DOI: $10.16995 /$ olh. 634 
From under the rug we can hear muffled conversation. Some of us kneel and lift the edges to peer in. The group pass the object between them, and as they hold it they peel back the foil and glance at the object inside. Each person describes what they gathered from this glimpse, then re-wraps the object and passes it on to waiting hands (Figure 6). No one who speaks can state its function with certainty, but they discuss its careful and complex workings, and argue about its possible use and manufacture. As the object moves around the circle it weaves its own story, moving backwards from a known present into the speculations of an uncertain past.

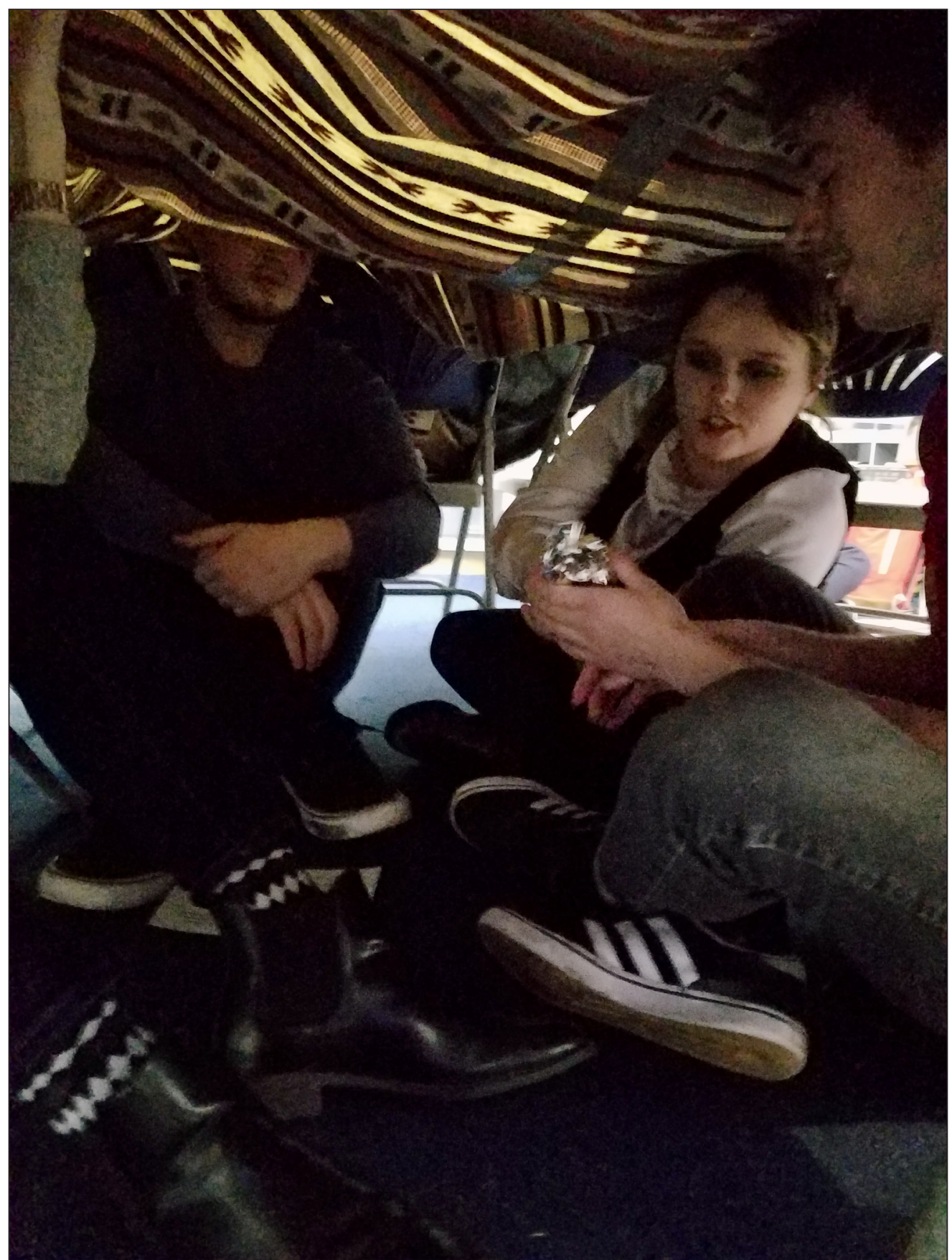

As well as an exhibition space, the remember rooms provide space to gather and share oral histories. Each new member of the community contributes her personal recollections to the communal memory to become part of a shared history retold in these gatherings. In this extract, the perspective and presence of children establishes the pedagogical intent of remembering, borne from the social necessity to recall what has been left behind. Amid this communality there is also spatial agency, with each child able to literally carve a comforting womb-like space for themselves where they feel adequately supported to focus on recollections of oppression and violence. These acts of remembering are viscerally painful and must be approached
Open Library of

Humanities

DOI: $10.16995 /$ olh. 634

Figure 6 The act of storytelling. Four people sit together on the floor in dim light. Above them is canopy of fabric which is held up by chairs in the background and their own hands, partially obscuring some of their faces. One person is holding an object wrapped in silver foil. The person next to them is leaning over to gesture towards the object while they speak. Photograph taken by the author 
carefully and slowly with the protective presence of a trained guide. But they are also a vitally important part of the collective writing of history which acknowledges and holds the memory of trauma. In all their complexity and conflict, these acts of remembering are "a communal voice of women telling their stories from their own perspective and for themselves" (Bammer, 2004: 79).

Once the story has run its spiral path back, we remove the rug and join the group on the floor as they unpeel the foil and outline the decision to select and wrap up a small plastic calculator. They describe choosing it for its presumed ubiquity as a cheap, mass produced tool of mathematical knowledge. The process of storytelling is described as an attempt to discard that existing knowledge and relay only what they could gather directly from the object itself. It was an attempt to set aside an intimate familiarity and encounter something as if for the first time. One member of the group voices their dismay at the meagre understandings gleaned from the object itself. We talk about how meaning is painstakingly drawn out from an object, and the myths that we construct in the absence of certainty.

Within the museum, the act of sharing an object through an exhibition produces meaning in a process which is neither neutral nor objective (Mason, 2005). Rather, the museum exhibition is part of what Emma Barker terms a culture of display which is both a form of "representation as well as a mode of presentation" (Barker, 1999: 13; cited in McCarthy, 2006). While objects are placed within the context of the exhibition in order to make specific meanings visible, in doing so they are reconstituted through those framing discourses. It is a transformation that Donald Preziosi (2006) associates with the act of passing an object across an exhibitionary threshold, which shifts and redefines significance and meaning.

This assignment of meaning, of interpretation and understanding, is a critical part of exhibition construction. Where such exhibitions are didactic, they silently assert the superiority of their underlying value systems, reinforcing the singular authoritarian voice of the institution. As Richard Sandell argues, museums "are undeniably implicated in the dynamics of (in) equality and the power relations between different groups through their role in constructing and disseminating dominant social narratives" (Sandell, 2007: 100). In response, engaged exhibition practices aim to establish museums as communicative and collaborative spaces, allowing essentialising practices to be unpicked and contested. ${ }^{9}$ In this expanded space of interpretation, multiple readings and memories might be given value, to make visible what Anthony Shelton refers to as "the fugitive nature of meaning" (Shelton, 2006: 79).

As we talk the calculator becomes incomprehensible in our hands. We are disquieted to confront the fact that the frameworks of our knowing are so lightly based on the innate qualities of the object we hold, and so deeply rooted in our life-worlds. We step back from this singular object to reflect on the acts of story-telling we carry with us into museums; the ways of knowing, experiences and memories which shape our understandings and frame each object we encounter. The horizon of expectation we establish for each object tempers and constrains possibilities of interaction.

At the level of the object, the movement towards multiplicity can be realised in the labelling of individual items, in forms which express polyvocality or invite interpretation. ${ }^{10}$ In her study of the National Museum of the American Indian in Washington, Claire Smith (2005) outlines how the discourses of colonialism inform museum exhibition design through the label, the boundary, and the metanarrative. For Smith, the presence of a label, however multiple its voice, provides easy resolution. It implies that the world can be understood through these fragments and that it can be ordered and known. To remove a label then, might grant objects what Stephen Bann calls "typological exuberance" (Bann, 2003: 125), where rationales of chronology or taxonomy can no longer be assumed. As observed by Sharon Macdonald (2006), this opens up greater space for meaning beyond that assigned or designated, where personal associations and memories are held and validated as ways of knowing.

Someone shares how difficult it is to disregard what has been known and to quiet the voice of experience even fleetingly. We speculate on the events which would be necessary to make this

9 For further consideration of the constructivist approach to exhibition practices which build on the concerns about democratizing and demystifying the museum and improving accessibility see, among others, HooperGreenhill (2000) and Phillips (2005).

10 The ethical importance of labelling, whether this takes on an academic voice which quashes the opportunity for dissent and suppresses its subjectivity or invites polyvocality, is further discussed in Moser (2010), Ravelli (2007), Leahy (2008), and McClusky (2012); cited in Gazi (2014).
Open Library of

Humanities

DOI: $10.16995 /$ olh.634 
familiar object strange. The temporal distance of the deep past or distant future which would obscure technological understanding, or the rupture of loss brought about by devastation or disaster.

Smith's notion of 'boundary' examines how frameworks of knowledge, such as the technoscientific ideals of progress which were present in our sharing of the calculator and in the city-objects of the remember rooms, have informed the processes of collection and curation as well as the presentation of objects in an exhibition. Through the application of classification systems, judgements are made about what can be considered familiar, and in so doing they define that which is strange or other. As well as being informed by specific paradigms of knowing, any exhibition is "filtered through the tastes, interests, politics and states of knowledge of particular presenters at a particular moment in time" (Vogel, 1991: 201). Smith argues that there is an ethical imperative to make such subjectivity visible, as well as developing exhibitions which are founded on multiple knowledge construction and memory sharing practices.

As we try to imagine the experience of those without knowledge of this object, we attempt to inhabit a society outside of the time or space of this ubiquity. We find it easier to call upon the imaginaries of the apocalypse than to conceive of a present outside of these paradigms of knowing. We struggle with the challenge of seeing the edges of our life-worlds as anything but universal.

Museums and their collections embody and exhibit social values, and their authority extends far beyond the institutional boundary (Hooper-Greenhill, 2000). As detailed by Susan Crane (2000) the exhibition is incorporated into the extra-institutional memory of its visitors, informing wider social practices by legitimising the values it demonstrates. Through her notion of the 'metanarrative' Smith examines the authority of the institution which is established through control over the exhibition, and the authority this confers onto the corporations and individuals, economic and political systems that such institutions are associated or inculcated with. This poses the critical question of how the museum as an institution might leverage its position of cultural privilege, and whether the act of bringing practices or groups within the museum divests or confers control, or whether it simply legitimises the position of the institution as an arbiter of knowledge.

As we attempt to reflect on the installation together, we stumble over the disjunction between those constructing the narrative and those outside the story being told. Someone talks about storytelling as a communal act, a passing along of a way to read the world. The group inside the space of storytelling speaks about how it was a mutual construction, a building up and reinforcement of both object and self. But those who stand outside, holding up the fabric of the rug and maintaining the act of shelter, can talk only about the fragmented moments they overheard (Figure 7).

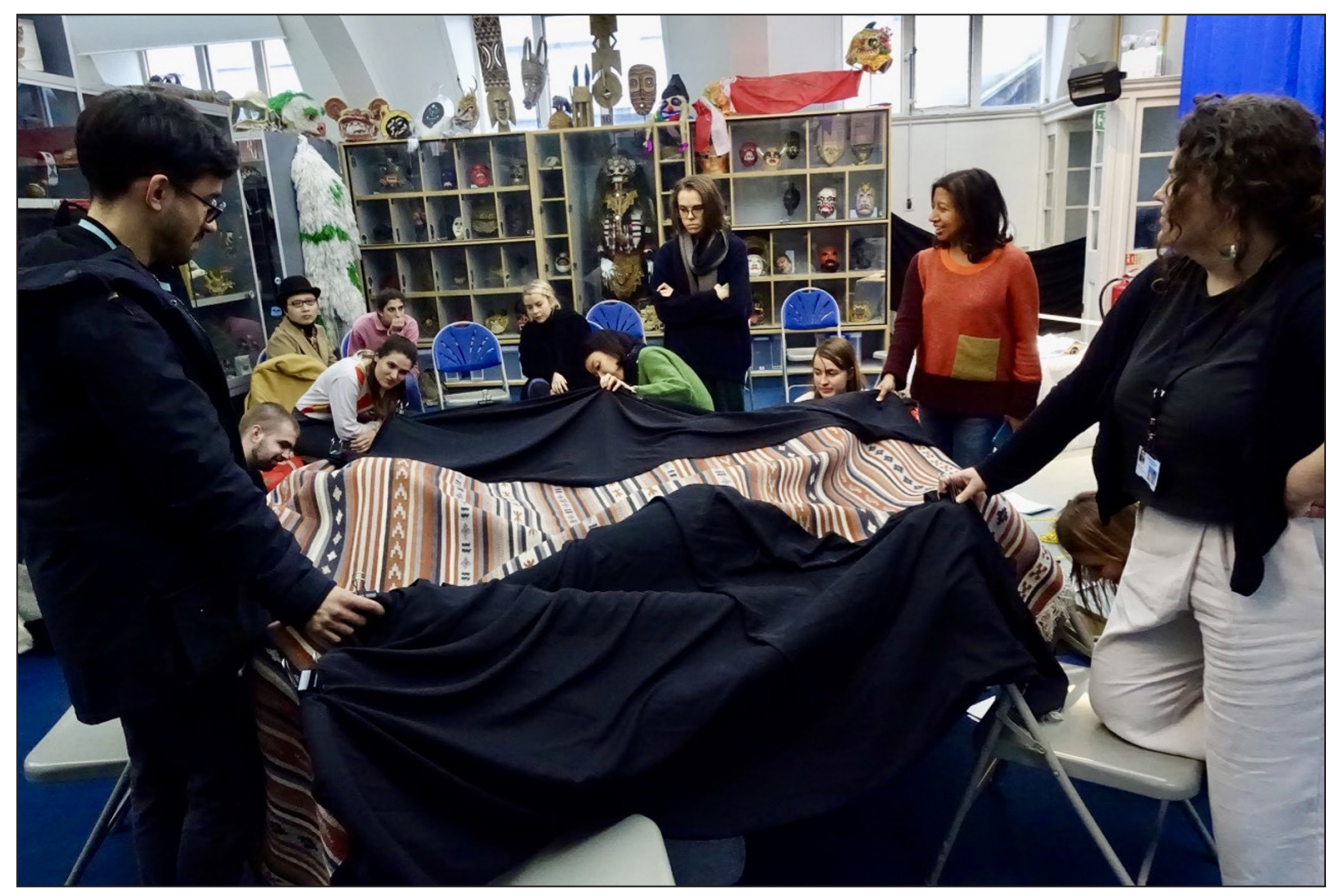

Open Library of

Humanities

DOI: $10.16995 /$ olh.634
Figure 7 The constructed shelter. Some rugs and pieces of black fabric are draped over folding chairs, held in place by three people who surround the circle of chairs. The fabric creates a canopy which hides what is happening beneath it. In the background, several people sit on chairs or crouch down in order to look under the fabric. One person lifts up a corner of the fabric in order to peer underneath. Reproduced by permission of Dan Byrne-Smith. 
The potential of sf to make evident the subjectivity of meaning is celebrated by Raffaella Baccolini, who finds utopian promise in sf's depiction of history and memory, providing alternatives to the hegemony of social order and narratives of colonialism which fix and essentialise, "to dismantle the singleness of its discourse, while remaining attuned to the plurality of visions and limits of the past" (Baccolini, 2003: 127). In this re-enactment of the science fictional museum, the act of exhibiting an object is performed as an act of storytelling. In doing so, the concept of intrinsic frameworks of knowledge or empirical understandings are unpicked, and all interpretations of the object under discussion are understood to be subjective. Most critically, this performance of storytelling identifies the construction of meaning as an act which generates a shared narrative, whist also acknowledging that this story and the meaning it assigns are not universal.

This act of performing a museum of sf created a space to develop meaning through narrative estrangement, and reflect on these same processes present within museum exhibitions. As a prompt for critical reflection on meaning making, it is an act which might support wider efforts to question the power inherent in exhibitions which construct and validate ways of understanding the world, as well as resonating with works which challenge or dismantle the presumed ubiquity of knowledge systems within and beyond museum institutions. While they are critical and valuable, such efforts to construct alternate forms of museum engagement and reconstitute the ideological inherence of museums must also critically question whether the communication of life-worlds other than our own is possible, or even desirable, within such institutional and exhibitionary frameworks.

\section{THE WORKSHOP}

The rug is dragged back down onto the floor. The chairs are folded and stacked in a corner. The bird, nest and calculator are handed back to the museum curator, and returned to their glass fronted cabinets. As we shrug on coats and bags, the room resettles into our absence.

In our restaging of these science fictional museums, we fleetingly established a new spatial context within which the acts of collection, curation and exhibition could be considered. Albeit brief, each of these interventions was an act of architectural design drawn from an imagined future and recast in the ad-hoc materials of the present. As we constructed, dismantled, and remade this space of the museum, we shifted the terms of encounter with the objects that it contains.

Christine Boyer defines the museum as a memory device, which utilises architectural design to construct meaning through spatial associations or sequential arrangements, in order to establish a narrative of history (Boyer, 1996: 133). It is an act of temporal location accompanied by spatial qualities of scale, light, material, and acoustics to create a context within which the exhibited objects are understood (Swain, 2018: 217). In this way, space supports the construction of meaning, and as Beverly Serrell claims, "design plays a crucial role - not just in presenting content, but in actually creating it" (Serrell, 2017: 33). But the museum is also a social and cultural product which is continually reproduced through use. As discussed by Jones and MacLeod (2016) the architectural design of a museum is a product of the social, cultural, economic and political systems within which it was developed. As a consequence it reflects and materialises attitudes towards objects and knowledges, which impacts on the way that the cultures represented through those objects are perceived (Gazi, 2014). So, the museum is a doubled act of preservation: it preserves the curated object, and, through its architectural framing, it re-performs the social system within which it was constructed.

Within the imagined futures of sf, the symbolic role of museum architecture and the sociopolitical systems it embodies are expressed with startling clarity. The associations prompted by architectural design are palpably present: in the churches converted into museums of propaganda and industry in George Orwell's 1984 (1949) and Olaf Stapledon's Last and First Men (1930), or the lens-shaped architectural absurdity which was once humanity's largest building in Samuel Delany's Nova (1968). In these fictions the design of the museum is a spatial shorthand, an evocative expression of a cultural attitude towards these material signifiers of our present or the fictional past. But while these structures are didactic expressions of ideological certainty, the museum in sf is not always located in such a grandiose form. The gathered remnants of pre-disaster life in Emily St. John Mandel's Station Eleven (2014) displayed in the corner of pen Library of

Humanities

DOI: 10.16995 /olh.634 
the airport concourse which serves as refuge, or the writings hidden under the floorboards of the Barren House in Suzette Haden Elgin's Native Tongue (1984), are collections held close in spaces of community gathering, founded not on appropriated objects and bodies but on collective acts of critical self-narration. Robert Crossley notes in his examination of museums in sf, "in the showcases of science fiction's museums we are chiefly on display" (Crossley, 1991: 99), and while he refers primarily to the remnants of the reader's present encased in the glass cabinets of imagined futures, these museums in sf serve also to hint at the possibility of a space to critically curate our own histories; the museum institution dissolved and reconstituted as a science-fictional space of situated self-awareness.

Throughout this workshop the act of revealing, the sense of discovery, and the reframing of objects, all worked as a tangible acting out of some of the processes of cognitive estrangement present in sf texts. As we negotiated the complexity of our own readings of familiar objects in an unfamiliar setting it created an opportunity to reflect on our own pre-existing knowledge and experience of that specific object and material culture. It provided a vital space to discuss our own cultural assumptions, biases and methods of interpretation while also acknowledging the processes of selection, preservation, and display which had brought that object and this group together.

The resultant installations were the result of a haphazard throwing together of people and materials, and as such they project a sense of impermanence and fragility in each configuration. This quality of 'throwntogetherness' is defined by Doreen Massey in relation to urban environments where it can be found in the unlikely juxtapositions of buildings or the uncoordinated being together of neighbours. For Massey (2005) this is a vital part of the productiveness of spatiality, which opens up spaces of possibility through encounters with diversity and difference.

This act of collective construction created an opportunity to encounter meaning in ways which were not framed by the assumed hierarchies of knowledge held within the museum space. Rather, we were able to reflect on the subjectivity of meaning in a forum which valued personal association and memory. As an inadvertent exercise in polyvocality it responded to some of the challenges identified by Kevin Coffee to recognise multiple voices within institutional forms which "arose to enable the hegemony of a narrow cultural narrative" (Coffee, 2006: 446), and the wider need to find new ways to evoke individual memories to dismantle dominant mythologies (Davison, 2005). In this way, this act of critical speculative thinking and design temporarily responded to Lola Young's call to shift the terms of museum engagement and empowerment. Rather than extending an invitation into the pre-existing space of the museum, laden with histories of bias and oppression, Young calls for "self-determined critical interventions that enrich our understanding of the ways in which history is made and represented" (Young, 2003: 211).

This article and the workshop it is based upon set out to consider whether the science-fictional can provide a critical perspective on acts of collection, curation and exhibition, and to ask what the museums of science fiction futures can offer those of us concerned with the role and responsibility of the museum in the present. I leave with a startling sense of joy brought into being by unanticipated depths and unforeseen directions. In the interventions we constructed it is possible to glimpse how engagement with the imagined museums of science fiction might allow us to restage the role and form of the museum as sites for the memory of the present, to value individual forms of storytelling. Here I find hope that the tangible staging of these spaces, however fleeting, demonstrates the critical potential present in multiple forms of knowing and the radical possibility inherent in collective acts of remaking.

\section{ACKNOWLEDGEMENTS}

The installations and discussions which form the basis of this article were the work of art and curation students from University of the Arts London and this work was made possible by the staff of the Horniman Museum.

My sincere thanks to Dr Dan Byrne-Smith for many fascinating conversations around sf and museums which both inspired and informed this work. This article builds upon work presented at the 'Museum Engagement as Speculative Design' symposium at Camberwell College of Arts pen Library of

Humanities

DOI: $10.16995 /$ olh.634 
in 2019 organized by Dr Byrne-Smith, and owes much to the work of the other symposium presenters: Jason Cleverly, Amy Cutler, Florence Okoye, Mariana Pestana, and Fiona Raby.

My thanks to the anonymous reviewers for your constructive and generous comments. My continued thanks to the sf communities which I am privileged to be part of, including the Beyond Gender Research Collective, LSFRC, and all those who shared ideas at 'Life in the Glasshouse: Splintered Memories' whose thoughtful work shaped this paper. Particular thanks to Glyn Morgan and Katie Stone for your passionate and critical insights into museums in, of, and as sf. As ever, my thanks to Maggie Butt and David Roberts for your support and invaluable help refining this work.

\section{COMPETING INTERESTS}

The author has no competing interests to declare.

\section{AUTHOR AFFILIATIONS}

Amy Butt (D) orcid.org/0000-0002-1762-2768

University of Reading, GB

\section{REFERENCES}

Aldridge, A 1977 Myths of Origin and Destiny in Utopian Literature: Zamiatin's We. Extrapolation, 19(1): 68-75. DOI: https://doi.org/10.3828/extr.1977.19.1.68

Arendt, H 1973 The Origins of Totalitarianism. Orlando: Houghton Mifflin Harcourt.

Baccolini, R 2003 'A Useful Knowledge of the Present is Rooted in the Past': Memory and Historical Reconciliation in Ursula K LeGuin's The Telling. In: Moylan, T and Baccolini, R (eds.) Dark Horizons: Science Fiction and the Dystopian Imagination. New York; London: Routledge. pp. 113-134.

Bammer, A 2004 Partial Visions: Feminism and Utopianism in the 1970s. New York; London: Routledge.

Bann, S 2003 The Return to Curiosity: Shifting Paradigms in Contemporary Museum Display. In: McClellan, A (ed.) Art and Its Publics: Museum Studies at the Millennium. Malden; Oxford; Victoria: Blackwell Publishing Ltd. pp. 117-132. DOI: https://doi.org/10.1002/9780470775936.ch5

Baraitser, L 2017 Enduring Time. London; New York: Bloomsbury Publishing.

Barker, E 1999 Contemporary Cultures of Display. New Haven; London: Yale University Press.

Barringer, T and Flynn, T 2012 Colonialism and the Object: Empire, Material Culture and the Museum. London; New York: Routledge. DOI: https://doi.org/10.4324/9780203350683

Barthes, R and Duisit, L 1975 An Introduction to the Structural Analysis of Narrative. New Literary History, 6(2): 237-272. DOI: https://doi.org/10.2307/468419

Beauchamp, G 1983 Zamiatin's We. In: Rabkin, ES, Greenberg, MH, and Olander, JD (eds.) No Place Else: Explorations in Utopian and Dystopian Fiction. Southern Illinois University Press.

Beaumont, M 2012 The Spectre of Utopia: Utopian and Science Fictions at the Fin de Siècle. Oxford: Peter Lang.

Bennett, T 2013 The Birth of the Museum: History, Theory, Politics. London; New York: Routledge. DOI: https://doi.org/10.4324/9781315002668

Bould, M 2019 Afrofuturism and the Archive: Robots of Brixton and Crumbs. Science Fiction Film \& Television, 12(2): 171-193. DOI: https://doi.org/10.3828/sftv.2019.11

Boyer, MC 1996 The City of Collective Memory: Its Historical Imagery and Architectural Entertainments. Cambridge; London: MIT Press.

Bradbury, R 1953 Fahrenheit 451. Ballantine Books.

Canavan, G 2014 Retrofutures and Petrofutures. In: Barrett, R and Worden, D (eds.) Oil Culture. Minneapolis: University of Minnesota Press. pp. 331-349. DOI: https://doi.org/10.5749/ minnesota/9780816689682.003.0017

Coffee, K 2006 Museums and the Agency of Ideology: Three Recent Examples. Curator: The Museum Journal, 49(4): 435-448. DOI: https://doi.org/10.1111/j.2151-6952.2006.tb00235.x

Crane, SA 2000 Museums and Memory. Stanford University Press.

Crane, SA 2006 The Conundrum of Ephemerality: Time, Memory, and Museums. In: Macdonald, S (ed.) A Companion to Museum Studies. Malden; Oxford; West Sussex: John Wiley \& Sons, Ltd. pp. 98-109. DOI: https://doi.org/10.1002/9780470996836.ch7

Crossley, R 1991 In the Palace of Green Porcelain: Artifacts from the Museums of Science Fiction. In: Shippey, TA (ed.) Fictional Space: Essays on Contemporary Science Fiction. Wiley-Blackwell. pp. 76-106.
Open Library of

Humanities

DOI: $10.16995 /$ olh.634 
Crownshaw, R 2017 Speculative Memory, the Planetary and Genre Fiction. Textual Practice, 31(5): 887-910. DOI: https://doi.org/10.1080/0950236X.2017.1323484

Csicsery-Ronay, I 1986 Zamyatin and the Strugatsky: The Representation of Freedom in We and The Snail on the Slope. In: Kern, G (ed.) Zamyatin's We: A Collection of Critical Essays. Ardis. pp. 236-259.

Davison, P 2005 Museums and the Re-Shaping of Memory. In: Corsane, G (ed.) Heritage, Museums and Galleries: An Introductory Reader. London; New York: Routledge.

Delany, SR 1968 Nova. Doubleday.

Dunne, A and Raby, F 2013 Speculative Everything: Design, Fiction, and Social Dreaming. Cambridge Mass.; London: MIT press.

Edwards, C 2015 Peak oil in the Popular Imagination. Alluvium, 4(4). DOI: https://doi.org/10.7766/ alluvium.v4.4.02

Elgin, SH 1984 Native Tongue. DAW Books.

Eshun, K 2003 Further Considerations of Afrofuturism. CR: The New Centennial Review, 3(2): 287-302. DOI: https://doi.org/10.1353/ncr.2003.0021

Fyfe, G 2006 Sociology and the Social Aspects of Museums. In: Macdonald, S (ed.) A Companion to Museum Studies. Malden; Oxford; West Sussex: John Wiley \& Sons, Ltd. pp. 33-49. DOI: https://doi. org/10.1002/9780470996836.ch3

Gazi, A 2014 Exhibition Ethics: An Overview of Major Issues. Journal of Conservation and Museum Studies, 12(1). DOI: https://doi.org/10.5334/jcms.1021213

Gearhart, SM 1979 The Wanderground: Stories of the Hill Women. Persephone Press.

Gheran, N 2014 Past History in the Dark Future. Romantic Heterotopias and the Preservation of Memories within the Dystopian City. Caietele Echinox, (27): 102-113.

Gomel, E and Weninger, SA 2004 Romancing the Crystal: Utopias of Transparency and Dreams of Pain. Utopian Studies, 15(2): 65-91.

Hooper-Greenhill, E 2000 Changing Values in the Art Museum: Rethinking Communication and Learning. International Journal of Heritage Studies, 6(1): 9-31. DOI: https://doi.org/10.1080/135272500363715

Hutchings, W 1981 Structure and Design in a Soviet Dystopia: HG Wells, Constructivism, and Yevgeny Zamyatin's 'We'. Journal of Modern Literature, 9(1): 81-102.

Jameson, F 2005 Archaeologies of the Future: The Desire Called Utopia and Other Science Fictions. New York: Verso.

Jones, GA 1999 Deconstructing the Starships: Science, Fiction and Reality. Liverpool: Liverpool University Press. DOI: https://doi.org/10.5949/liverpool/9780853237839.001.0001

Jones, L 2018 Into the Blue Depths: Glass Mysticism in Yvegeny Zamyatin's 'We'. Paper delivered at the London Science Fiction Research Community Conference 2018.

Jones, P and MacLeod, S 2016 Museum Architecture Matters. Museum and Society, 14(1): 207-219. DOI: https://doi.org/10.29311/mas.v14i1.635

Ketterer, D 1998 The Editor's Slant on 'The Time Machine'. Science Fiction Studies, 25(1): 155-158.

Khanna, LC 1984 Frontiers of Imagination: Feminist Worlds. Women's Studies International Forum, 7(2): 97-102. DOI: https://doi.org/10.1016/0277-5395(84)90063-3

Leach, R 2002 What happened at home with art: Tracing the experience of consumers. In: Painter, C (ed.) Contemporary Art and the Home. London; New York: Routledge. pp. 153-80. DOI: https://doi. org/10.4324/9781003085065-10

Leahy, HR 2008 Under the Skin. Museum Practice Magazine: MP, (43): 36-40.

Macdonald, G 2014 Improbability Drives: The Energy of SF. Paradoxa, 26: 111-144.

Macdonald, S 2006 Collecting Practices. In: Macdonald, S (ed.) A Companion to Museum Studies. Malden; Oxford; West Sussex: John Wiley \& Sons, Ltd. pp. 81-97. DOI: https://doi. org/10.1002/9780470996836.ch6

Mandel, ESJ 2014 Station Eleven. Pan Macmillan.

Mason, R 2005 Museums, Galleries and Heritage: Sites of Meaning Making and Communication. In: Corsane, G (ed.) Heritage, Museums and Galleries: An Introductory Reader. London; New York: Routledge. pp. 200-214. DOI: https://doi.org/10.4324/9780203326350_chapter_16

Massey, DB 2005 For Space. London; California: SAGE.

McCarthy, C 2006 Hailing the Subject: Maori Visitors, Museum Display and the Sociology of Cultural Reception. New Zealand Sociology, 21(1): 108.

McClintock, JI 1977 United State Revisited: Pynchon and Zamiatin. Contemporary Literature, 18(4): 475. DOI: https://doi.org/10.2307/1208173

McClusky, PZ 2012 "Why is this here?”: Art Museum Texts as Ethical Guides. In: Marstine, J (ed.) The Routledge Companion to Museum Ethics: Redefining Ethics for the Twenty-First Century Museum. London; New York: Routledge. pp. 317-334.

Miller, WM 1959 A Canticle For Leibowitz. Lippincott.

Moser, S 2010 The Devil is in the Detail: Museum Displays and the Creation of Knowledge. Museum Anthropology, 33(1): 22-32. DOI: https://doi.org/10.1111/j.1548-1379.2010.01072.x
Open Library of

Humanities

DOI: $10.16995 /$ olh. 634 
Muller, L 2013 Speculative Objects: Materialising Science Fiction. In: Fisher, L, Cleland, K, and Harley, R (eds.) Proceedings of the 19th International Symposium of Electronic Art. Sydney, ISEA International.

Orwell, G 1949 1984. Penguin Books.

Parrinder, P 1973 Imagining the Future: Zamyatin and Wells. Science Fiction Studies, 1(1): 17-26.

Parrinder, P 1995 Shadows of the Future: H.G. Wells, Science Fiction, and Prophecy. New York: Syracuse University Press.

Phillips, R 2005 Re-Placing Objects: Historical Practices for the Second Museum Age. Canadian Historical Review, 86: 83-110. DOI: https://doi.org/10.3138/CHR/86.1.83

Preziosi, D 2006 Art History and Museology. In: Macdonald, S (ed.) A Companion to Museum Studies. Malden; Oxford; West Sussex: John Wiley \& Sons, Ltd. pp. 50-63. DOI: https://doi. org/10.1002/9780470996836.ch4

Ravelli, L 2007 Museum Texts: Communication Frameworks. London; New York: Routledge. DOI: https://doi. org/10.4324/9780203964187

Rieder, J 2012 Colonialism and the Emergence of Science Fiction. Middletown: Wesleyan University Press.

Sandell, R 2007 Museums and the Combating of Social Inequality: Roles, Responsibilities, Resistance. In: Watson, S (ed.) Museums and their Communities. London; New York: Routledge, 95-113.

Serrell, B 2017 Judging Exhibitions: A Framework for Assessing Excellence. London; New York: Routledge. DOI: https://doi.org/10.4324/9781315425818

Shaw, DB 2000 Amazons and Aliens: Feminist Separatism and the Future of Knowledge. In: Shaw, DB (ed.) Women, Science and Fiction. Hampshire; New York: Palgrave. pp. 128-157. DOI: https://doi. org/10.1057/9780230287341_7

Shelton, AA 2006 Museums and Anthropologies: Practices and Narratives. In: Macdonald, S (ed.) A Companion to Museum Studies. Malden; Oxford; West Sussex: John Wiley \& Sons, Ltd. pp. 64-80. DOI: https://doi.org/10.1002/9780470996836.ch5

Smith, C 2005 Decolonising the Museum: the National Museum of the American Indian in Washington, DC. Antiquity, 79(304): 424-439. DOI: https://doi.org/10.1017/S0003598X00114206

Sobchack, V 1988 Cities on the Edge of Time: The Urban Science Fiction Film. East-West Film Journal, 3(1): 4-19.

Sontag, S 1964 The Imagination of Disaster. Commentary, 40(4).

Stapledon, 01930 Last And First Men. Methuen.

Stone, K 2020 The Time Machine and the Child: Imperialism, Utopianism, and H. G. Wells. Fantastika Journal, 4(1): 17.

Suvin, D 1979 Metamorphoses of Science Fiction: On the Poetics and History of a Literary Genre. Yale University Press.

Swain, H 2018 [2007] An Introduction to Museum Archaeology. Cambridge; New York: Cambridge University Press.

Vogel, S 1991 Always True to the Object, in our Fashion. In: Karp, I and Lavine, S (eds.) Exhibiting Cultures: The Poetics and Politics of Museum Display. Washington; London: Smithsonian Institution Press. pp. 191-204.

Wegner, PE 1993 On Zamyatin's We: A Critical Map of Utopia's Possible Worlds. Utopian Studies, 4(2): 94-116.

Wells, HG 2016 The Time Machine. Oxford University Press.

Williams, R 2014 Recognizing Cognition: on Suvin, Miéville, and the Utopian Impulse in the Contemporary Fantastic. Science Fiction Studies, 41(3): 617-633. DOI: https://doi.org/10.5621/sciefictstud.41.3.0617

Yaszek, L 2006 Afrofuturism, Science Fiction, and the History of the Future. Socialism and Democracy, 20(3): 41-60. DOI: https://doi.org/10.1080/08854300600950236

Young, L 2003 Rethinking Heritage: Cultural Policy and Inclusion. In: Sandell, R (ed.) Museums, Society, Inequality. London; New York: Routledge.

Zamyatin, Y 2007 We. New York: Random House Publishing Group.

Zimmerman, B 1983 Exiting from Patriarchy: The Lesbian Novel of Development. In: Abel, Elizabeth, Hirsch, Marianne, and Langland, Elizabeth (eds.) The Voyage In: Fictions of Female Development. Hanover; London: University Press of New England.
Open Library of

Humanities

DOI: $10.16995 /$ olh. 634
TO CITE THIS ARTICLE: Butt, A 2021 The Present as Past: Science Fiction and the Museum. Open Library of Humanities, 7(1): 9, pp. 1-18. DOI: https://doi.org/10.16995/ olh.634

Published: 14 April 2021

\section{COPYRIGHT:}

(c) 2021 The Author(s). This is an open-access article distributed under the terms of the Creative Commons Attribution 4.0 International License (CC-BY 4.0), which permits unrestricted use, distribution, and reproduction in any medium, provided the original author and source are credited. See http://creativecommons.org/ licenses/by/4.0/.

Open Library of Humanities is a peer-reviewed open access journal published by Open Library of Humanities. 